+ Common Services Agency, Information and Statistics Division. Scottish health statistics 1988. Edinburgh: ISD Publications, 1988

Tindal VR. Feffcoate's principles of gynaecology. 5th ed. London: Butterworth, 1987.

6 Sheldon MG, Rector AC, Boriman PA. The accuracy of age-sex registers in general practice. I R Coll Gen Pract 1984;34:269-71.

Standing P, Mercer S. Quinquennial cervical smears; every woman's right and every general practitioner's responsibility. Br Med $f$ 1984;289:883-6.

8 Rang EH, Tod EDM. Problems of cervical screening programmes. $f R$ Coll Gen Pract 1988;37:540-3.

Bowling A, Jacobsen B. Screening: the inadequacy of population registers. Br Med J 1989;298:545-6.

10 Pennington E, Wilcox RML. Immunisation, practice records and the white paper. I $R$ Coll Gen Pract 1988;38:515-6.

Nichols S. Women's preference for sex of doctor: a postal survey. $\mathcal{F} R$ Coll Gen Pract 1987;37:540-3.
12 Havelock C, Edwards R, Cuzick J, Chamberlain J. The organisation of cervical screening in general practice. $\mathcal{f} R$ Coll Gen Pract 1988;38:207-11.

3 Sanson CD, MacInerny J, Oliver V, Wakefield J, Yule R. Recall of women in a cervical screening programme: an estimate of the rate of response. British fournal of Preventive and Social Medicine 1975;29:131-4.

14 Pill R, French J, Harding K, Stott N. Invitation to attend a health check in a general practice setting: comparison of attenders and non attenders. $f R$ Coll Gen Pract 1988;38:53-6.

15 McAvoy B, Sharma S. Asian women and contraception. The Physician 1986;5:1067-8.

16 Nathoo V. Investigation of non-responders at a cervical screening clinic in Manchester. BrMed F 1988;296:1041-2.

17 Townsend P, Davidson N, eds. Inequalities in health. The Black report. 1st ed. England: Penguin, 1982

(Accepted 5 fune 1989)

\title{
Attendance and non-attendance for breast screening at the south east London breast screening service
}

\author{
James McEwen, Erica King, Graham Bickler
}

\begin{abstract}
Objectives-To ascertain the reasons for a low rate of response for breast screening.

Design-All relevant aspects of the organisational process examined, including general practitioners' notes. Non-responders visited and interviewed.

Setting-An inner city breast screening service working on the model advocated by the Forrest report.

Subjects - 288 Women aged 50-64 registered with several general practices and invited for screening by post.

Main outcome-Determination of factors important for success of breast screening programmes.

Results-After five women were excluded by their general practitioners the response rate was 129 out of $283(46 \%)$, but $99(35 \%)$ of the women did not receive their invitations because of inaccuracies in the family practitioner committee's database and general practitioners failing to check women's addresses completely.

Conclusions-Increased rates of response will depend on enabling general practitioners to check addresses and on an increased awareness of the importance of information.
\end{abstract}

\section{Introduction}

After the publication of the Forrest report ${ }^{1}$ and its acceptance by the Department of Health and Social Security, Camberwell Health Authority was identified as the site for the first breast screening centre in South East Thames Regional Health Authority. Screening started in 1988, but the rate of response was well below the $70 \%$ figure proposed as a target in the Forrest report. We followed up cohorts of women in several screening batches to identify the nature of the problem. The population register used as the basis of breast and other screening programmes was thought to be important. ${ }^{2}$

Description of screening system-The local scheme follows the methods recommended in the Forrest report. The family practitioner committee's computer produces screening batches - that is, lists of women aged 50-64 from several general practitioners who are to be invited for breast screening. These are sent to the individual general practitioners as prior notification lists for amendment to addresses, names, dates of birth, and unsuitability on clinical grounds. When the prior notification lists are returned the family practitioner committee's computer is updated and the revised list is sent to the screening office. This issues personalised invitations in the general practitioner's name with fixed appointment times. Women who do not attend are sent a second invitation. Women who have not attended after two letters of invitation are classed as non-attenders, and their general practitioners are sent a non-responder card for inclusion in their notes.

\section{Methods}

We examined each stage of the screening process. The numbers of women at each stage were checked from the records of the family practitioner committee and screening office. The prior notification lists that had been returned to the family practitioner committee by general practitioners were examined to ascertain how of ten addresses had been altered. The addresses of non-attenders whose invitations were not returned by the post office were checked in the postcode directory. The checked addresses that were found to exist were visited by two interviewers to identify and interview the occupier. The reasons for non-attendances were noted for all the non-attenders who were contacted, and they were offered a further invitation to attend for screening. General practitioners' records were checked to ascertain what further information they contained about the addresses of $(a)$ women whose invitations had been returned unopened by the post office; $(b)$ non-attenders whose addresses could not be found in the postcode directory; and $(c)$ non-attenders whose addresses were visited but who were found to have moved.

\section{Results}

The screening batches contained 288 women registered with several different practices. Seventeen out of 20 prior notification lists were returned. As a result, five of the 288 women were excluded from screening, 37 addresses had major changes made to them (sufficient to have otherwise led to non-delivery of the letter), and nine had minor changes. The figure summarises the results.

Overall, 283 women were sent invitations. Ten contacted the screening office to say that they would not be coming for screening (see table). A total of 44 invitations were returned unopened by the post office. When the general practitioners' notes for these 44 were examined, 17 contained major address changes, four minor changes, and 15 no changes. Eight sets of notes could not be found. No further follow up was undertaken for these women, though the family practitioner
Correspondence to: $\mathrm{Dr}$ Bickler.

$B r M e d ~ \mathcal{F} 1989 ; 299: 104-6$ 
committee initiated FP69 procedures, which entail removing them from the general practitioner's list unless she or he can provide a different address or is currently providing care for them.

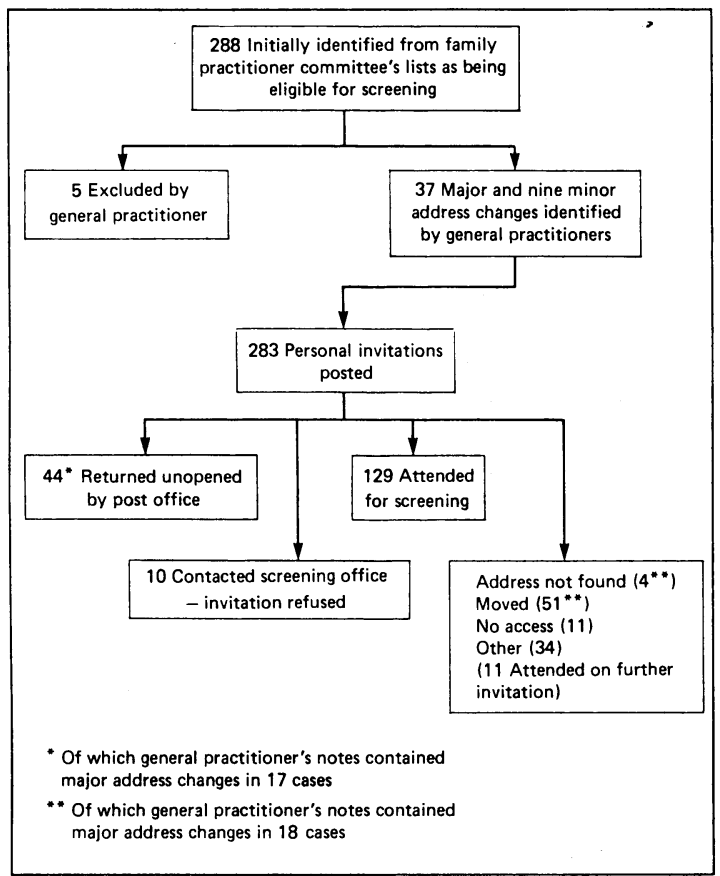

Flow chart of results of process for breast screening

Of the remaining 229 women, 129 attended for screening. When the addresses of the 100 nonattenders were checked against the postcode directory 66 were correct, 11 stated the name of a block of flats but gave no further information, 19 had other minor errors, and four could not be found.

The 96 addresses that existed were visited, and 85 of the occupiers were interviewed. Eleven either refused access or there was no one in on four successive visits. At 51 of the 85 addresses where the occupier was interviewed the woman on the invitation no longer lived there, and some had moved several years previously. In total, 99 of the women sent invitations were discovered not to be living at the address to which the invitation was sent.

When the general practitioners' notes were checked for the 51 women no longer living at the address given and the four whose addresses did not exist 18 contained major address changes, one a minor change, and 29 no changes. Seven sets of notes could not be found.

The table summarises the reasons for non-attendance offered by the 34 non-attenders who lived at the address stated and were interviewed. Failure to receive the invitation was not a problem. Two said that they

Stated reasons for non-attendance of women who contacted screening office (group A) and interviewed non-attenders (group B)

\begin{tabular}{lcc}
\hline Reason & $\begin{array}{c}\text { Group A } \\
(\mathrm{n}=10)\end{array}$ & $\begin{array}{c}\text { Group B } \\
(\mathrm{n}=34)^{\star}\end{array}$ \\
\hline Too old & 1 & 1 \\
Dead (information from relatives) & & 1 \\
No breast problems & & 2 \\
Fear or would rather not know & 1 & 7 \\
Recently screened & & 2 \\
Service problems & & 6 \\
No time & & 6 \\
Holidays & & 2 \\
Language & 6 & 4 \\
Dislike of doctors & 2 & 2 \\
Others or unspecified & & \\
Under treatment for breast cancer & & 2 \\
\hline
\end{tabular}

^Total greater than 34 because some women offered more than one reason. were ineligible for screening and 21 that they would like a further invitation for screening. Eleven subsequently attended.

\section{Discussion}

This is one of the first published studies of response rates for breast screening since the implementation of the national programme. Our main findings were that the overall response rate was 129 out of $283(46 \%)$ and that 99 out of $283(35 \%)$ women who were sent invitations did not actually receive them. Comparisons with other studies are difficult as they all use different population registers, but our results in general are worse than those reported elsewhere, though from discussions other inner city areas may have similar rates. Forty four (16\%) of our invitations were returned unopened by the post office. Elkind et al reported a figure of $13 \%$ for cervical cytology invitations in inner Manchester ${ }^{3}$; Hunt et al reported 9\% for breast screening in Edinburgh ${ }^{4}$; and Silman reported $14 \%$ in east London in a hypertension screening exercise. ${ }^{5}$

Similarly, the total rate of errors for addresses of $35 \%$ obtained by visiting non-responders was poor. Silman's figure was $26 \%{ }^{5}$; Fraser and Clayton showed that $17 \%$ of a family practitioner committee's addresses were inaccurate $e^{6}$; and Sheldon et al reported that $10 \%$ of the addresses in well kept age-sex registers were incorrect. ${ }^{\text {? }}$

There may be several reasons for our findings. In inner London population mobility is high and the accuracy of family practitioner committee's data on patient registration is lower than elsewhere. ${ }^{2}$ Family practitioner committees' registers may contain more errors now because of transcription errors when they were computerised. Finally, though addresses on general practitioners' medical record envelopes are known to be more accurate than those on the family practitioner committee's register, ${ }^{5}$ the general practitioners in our study identified only about half of the address changes that they could have when they were checking the accuracy of the prior notification lists. Of the 99 women who did not receive invitations, the general practitioners' notes contained evidence of an address change in 35 cases.

As the single largest contribution to increasing response rates may clearly be made by more accurate data support must be given to staff with responsibility at the family practitioner committee, in the screening office, and in general practice to check records. They all need to work together to devise the best approach to ensure that time and resources are available for this important task. Even thorough checking of general practitioners' notes, however, would not have solved the problem as there was no further information in the notes of 64 of the 99 women who did not receive their invitation. The solution to this aspect of the problem will take some time as it will mean creating a greater awareness of the importance of the accuracy of registration data among both patients and doctors.

Only 34 non-attenders who actually received invitations were interviewed, but the reasons they offered were similar to those identified elsewhere for nonattendance for cervical screening. ${ }^{8}$ As far as health education is concerned there are two important messages. The first is contained in the poster designed for the national breast screening programme, "Make sure your doctor has your correct address." The second lies in the finding that 11 of the non-responders attended for screening after being visited by the interviewers. If these women are counted as attenders the response rate for women known to have received invitations becomes 140 out of $184(76 \%)$. This suggests that general practitioners have an important role in counselling women whom they know have not attended 
for screening, and the existing computer program that generates a non-responder card for inclusion in nonattenders notes should be used to do this.

This small study confirms the views that were held by many people before the institution of the service, that in inner city areas where there is extensive mobility of people high rates of uptake will take some time to achieve.

We thank Beryl Bates, Susannah Badger, Heather Nunnerley, Tony Ruffell, the staff of the south east London breast cancer screening service, Lambeth, Southwark, and Lewisham Family Practitioner Committee, and the general practitioners who took part in this study.
1 Department of Health and Social Security. Breast cancer screening. London: HMSO, 1986. (Forrest report.)

2 Bowling A, Jacobsen B. Screening: the inadequacy of population registers [editorial]. Br Med f 1989;298:545-6.

3 Elkind A, Haran D, Eardley A, Spencer B. Computer-managed cervical cytology screening: a pilot study of non-attenders. Public Health 1987;101: 253-66.

4 Hunt SM, Alexander F, Roberts MM. Attenders and non-attenders at a breast screening clinic: a comparative study. Public Health 1988;102:3-10.

5 Silman AJ. Age-sex registers as a screening tool for general practice: size of the wrong address problem. Br Med f 1984;289:415-6.

6 Fraser RC, Clayton DG. The accuracy of age-sex registers, practice medical records and family practitioner committee registers. $\mathcal{J} R$ Coll Gen Pract 1981:31:410-9.

7 Sheldon MG, Rector AL, Barnes PA. The accuracy of age-sex registers in general practice. $\mathcal{I} R$ Coll Gen Pract 1984;34:269-71.

8 Eardley A, Elkind A, Spencer B, Haran D, Hobbs P, McGuinness H. Health education in a computer-managed cervical screening programme. Health Education fournal 1988;47:43-7.

(Accepted 6 fune 1989)

\section{Clinical medicine in revolution: $1-N e w$ elements in the old regime}

\section{John Gabbay}

The French Revolution totally reshaped medicine. Within three tumultuous decades much of what we now take for granted had become the hallmark of the new medicine pioneered in France. Hospitals were for large numbers of sick people to be investigated and treated; doctors examined patients routinely by techniques such as palpation, percussion, and auscultation; necropsy was a routine way of learning about the nature of diseases and explaining clinical findings; diseases were envisaged as lesions of the tissues that could be analysed experimentally with the hope of eradicating them altogether; statistical studies of patients and clinical trials were undertaken; and doctors were trained in both medicine and surgery and learnt their profession largely by working with established practitioners at the bedside. Yet before the revolution none of these statements would have been true. Moreover, there were equally fundamental changes in many other sciences and professions too. What happened to cause them?

As with any other aspect of the French Revolution the answer is always being reinterpreted. We still do not have any real understanding of how the social, political, philosophical, and economic elements were catalysed in the crucible of the French Revolution to create both a new form of medicine and a new science of the body. ${ }^{1}$ It is not difficult to see why there is no simple answer, for as the following account will show, the crucible contained a complex mixture of seething ingredients.

\section{Physicians' role}

Physicians in eighteenth century Paris played little part in hospitals. ${ }^{2}$ With their elaborate wigs and gold lace trim they depended for their living on the patronage of wealthy clients. ${ }^{3}$ Such patients did not expect, or permit, a physician to lay his hands on them. Rather, it was the physician's role to understand and advise on his client's whole way of life so as to keep him or her in good health according to a scholarly knowledge of ancient and modern writings on the body, health, and disease (box). ${ }^{47}$

By the 1780s progressive physicians were critical of the hidebound traditionalism of the medicine of the Parisian establishment. A new, more practical and entrepreneurial breed of doctor was emanating from the new courses in Holland and especially Scotland, which emphasised modern science over ancient wisdom and applied knowledge over arid theory. ${ }^{8}$ Why, these doctors asked, were the old guard still persisting with their ancient precepts when European medicine was bursting with new ideas? The answer may have been that many of their élite clientele still expected the traditional approach, which might help to explain why, when that élite later came to be overthrown, the old medical values that served them also disappeared. ${ }^{6}$

\section{Science of nosology}

The more progressive Parisian physicians were enthused by new theories from many quarters. One of the main features of eighteenth century medicine was the widespread attempt to describe diseases systematically (the science of nosography) and to understand their causes-sometimes, as with the work of Morgagni, by postmortem dissections. ${ }^{9}$ Physicians

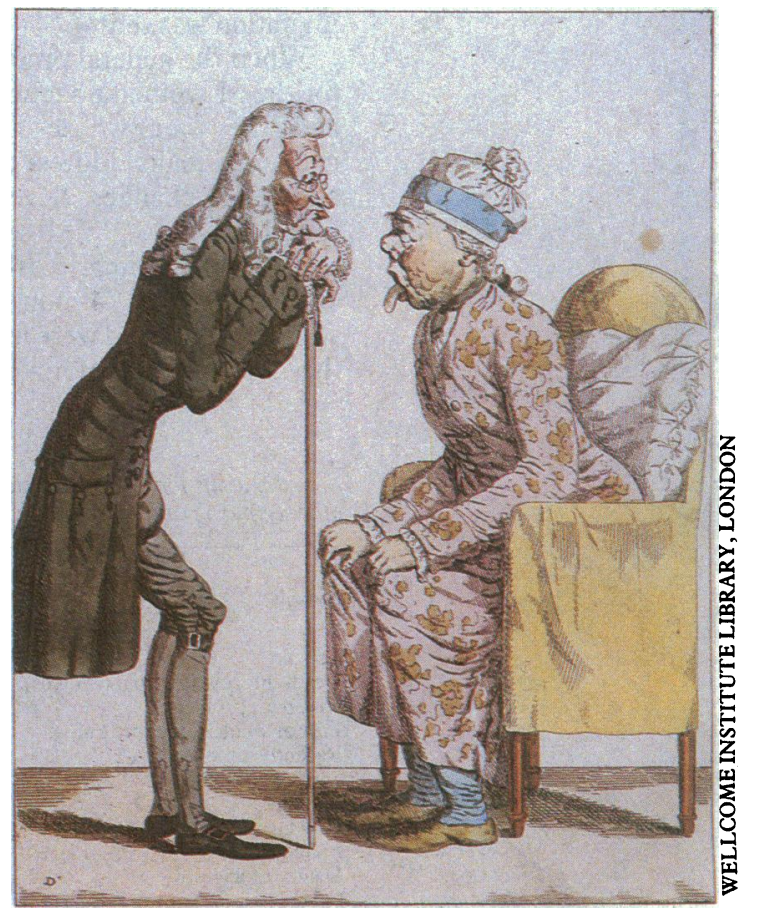

Physician visits a hypochondriac. Establishment physicians were often the butt of satire in the ancien régime as they had been in Molière's plays-for example, L'Amour Médecin (box $)^{4}{ }^{24}$
St Mary's Hospital Medica

School, London W2 1NY 